\title{
Photoacoustic Imaging
}

National Cancer Institute

\section{Source}

National Cancer Institute. Photoacoustic Imaging. NCI Thesaurus. Code C116749.

An imaging technique during which non-ionizing pulses are delivered into tissue and the resulting ultrasonic waves are detected and converted into images. 